\section{PTU-182 SPECIALIST CARE OF IN-PATIENTS WITH NON-VARICEAL UPPER GASTROINTESTINAL BLEEDING IS ASSOCIATED WITH A SIGNIFICANT SHORTER LENGTH OF STAY - A PROSPECTIVE ANALYSIS}

SV Venkatachalapathy*, R Bright, G Chung-Faye, P Dubois, I Forgacs, RP Logan, B Hayee. Gastroenterology, King's College Hospital, London, UK

\subsection{6/gutjnl-2014-307263.256}

Introduction Acute upper gastrointestinal bleeding (UGIB) is a common medical emergency that has a $10 \%$ mortality rate, ${ }^{1}$ requiring specialist input and management. ${ }^{2}$ We conducted a retrospective review last year which showed that the mean length of stay (days) was shorter in the GI group: $5.5 \pm 5.7$ vs $15.7 \pm$ $20.8(\mathrm{p}=0.02){ }^{3}$ We conducted a prospective analysis to assess if the above results held true.

Methods A prospective review of case-notes (Electronic patient record-EPR) was conducted for all patients admitted to Kings College hospital with suspected UGIB between January and September 2013. Patients were divided as to whether they came immediately under the care of Gastroenterologists (GI) or general physicians (non-GI) after initial evaluation in the Acute Admission Unit. Patients were assigned on the basis of bed availability in a ward-based system. Statistical comparisons were made as appropriate with two tailed t-test or chisquared test.

Results 138 patient episodes were reviewed of which 63 and 75 were treated by GI and Non-GI physicians. The two groups were broadly similar in their baseline characteristics. Mean length of stay (days) was significantly shorter in the GI group: $6.6 \pm 5.6 \mathrm{Vs} 10.66 \pm 11.3(\mathrm{p}=0.006)$. Other comparators are shown in the table.

Conclusion The length of stay of patients with UGIB is significantly shorter when receiving specialist care. In line with previous reports, ${ }^{4}$ we found that the incidence of UGIB was higher in males. Patients managed by GI physicians received less blood transfusion compared to the Non-GI physicians. The time to endoscopy was significantly shorter when receiving specialist care. Mortality rates in both groups compared favourably to the national average.

\section{REFERENCES}

1 CG141

2 Scope for improvement: A toolkit for a safer Upper Gastrointestinal Bleeding (UGIB) service. www.bsg.org.uk

3 Venkatachalapathy SV, Grasso N, Hayee B et al., Specialist care of in-patients with non-variceal upper gastrointestinal bleeding is associated with a dramatically shorter length of stay. Gut 2013;62:A10 doi:10.1136

4 Lanas A, García-Rodríguez LA, Polo-Tomás M et al., Am J Gastroenterol 2009; 104:1633-41

Disclosure of Interest None Declared.

\begin{tabular}{llll}
\multicolumn{4}{l}{ Abstract PTU-182 Table $\mathbf{1}$} \\
\hline Clinical Factors & GI $(\mathbf{n}=63)$ & Non-GI $(\mathbf{n}=75)$ & P value \\
\hline Age (years) & $58.15 \pm 18.69$ & $64.6 \pm 17.1$ & 0.03 \\
Male:Female & $51: 12$ & $42: 33$ & 0.03 \\
Rockall score & $3.16 \pm 2.05$ & $3.05 \pm 2.2$ & 0.70 \\
Haemoglobin & $93.9 \pm 37.10$ & $93.2 \pm 36.4$ & 0.86 \\
Blood Transfusion & $1.57 \pm 1.73$ & $2.26 \pm 2.52$ & 0.04 \\
Time to endoscopy (days) & $1.11 \pm 1.65$ & $2.19 \pm 1.9$ & 0.0007 \\
Mortality ascribed to UGIB & $3(4.7 \%)$ & $4(5.3 \%)$ & 0.8 \\
\hline
\end{tabular}

\section{PTU-183 DYSPHAGIA WITH NORMAL ENDOSCOPIC APPEARANCES - COULD WE DO BETTER?}

V Sehgal*, M Abayalingam, H Alexander, A Mitra, I Ahmed, B Krishnan, NV Someren, K Besherdas. Gastroenterology, Chase Farm Hospital, London, UK

\subsection{6/gutjnl-2014-307263.257}

Introduction Dysphagia is an 'alarm symptom' that merits prompt investigation by gastroscopy to exclude cancer. Cases in whom cancer is diagnosed at endoscopy in the UK are 'fast tracked' for multidisciplinary team discussion to plan future management. If endoscopy shows no cancer or intrinsic lesion (peptic stricture, oesophageal ring or web), the cause is usually secondary to oesophageal dysmotility. It is recommended that this group of patients should receive a trial of anti-reflux therapy to exclude refluxrelated dysmotility. If no improvement in symptoms is seen patients should be referred for oesophageal physiology studies.

Methods To assess the number of patients who underwent a gastroscopy for dysphagia that had no intrinsic cause found and to evaluate if these patients were managed in line with recommendations.

A retrospective analysis of all patients who underwent a gastroscopy for an indication that included dysphagia at Chase Farm Hospital over a 3-month period (April-June 2012) was performed. Data was obtained from endoscopy reports via the Unisoft GI Reporting Tool (Middlesex) and clinic outcome letters. Intrinsic oesophageal causes for dysphagia were said to be cancer, benign oesophageal stricture and eosinophillic oesophagitis (EE).

Results 106 patients (37 male, 69 female), median age 66 years, were investigated. 28 (26.4\%) had an intrinsic cause for dysphagia - benign oesophageal stricture 18 (17\%), cancer 8 (7.5\%) and EE 2 (1.9\%). 78 (73.5\%) patients had no intrinsic cause - reflux oesophagitis $26(32.5 \%)$, Barrett's oesophagus $2(2.5 \%)$, hiatus hernia 28 (35\%), gastritis/duodenitis 39 (48.8\%), normal $22(27.5 \%)$ and other $13(16.3 \%) .55$ (70\%) of these patients had no follow-up organised after endoscopy. The remaining had clinic review 20 $(25.6 \%)$, repeat endoscopy $4(5 \%)$ or referral for oesophageal physiology studies $1(1.3 \%) .30(38.5 \%)$ patients with no intrinsic cause were prescribed anti-reflux medication after endoscopy. 19 $(63.3 \%)$ of these patients had no further follow-up. The remaining had clinic review $9(30 \%)$ or a repeat endoscopy 2 (6.7\%); none were sent for oesophageal physiology studies.

Conclusion In this study, $75 \%$ of patients with dysphagia had no intrinsic cause identified. The majority of patients are discharged from the service without an accurate diagnosis or management recommendation. Our study highlights important shortcomings in the management of patients with a benign cause of dysphagia. We recommend that patients presenting with dysphagia who at endoscopy have no intrinsic cause, be prescribed acid suppression therapy followed by clinical review, and if symptoms persist be considered for oesophageal physiological studies.

Disclosure of Interest None Declared.

\section{PTU-184 RESTRICTIVE VERSUS LIBERAL BLOOD TRANSFUSION FOR ACUTE UPPER GASTROINTESTINAL BLEEDING: CLUSTER RANDOMISED FEASIBILITY TRIAL}

${ }^{1} \mathrm{~V}$ Jairath*, ${ }^{2} \mathrm{~B}$ Kahan, ${ }^{3} \mathrm{~A}$ Gray, ${ }^{2} \mathrm{C}$ Dore, ${ }^{4} \mathrm{~K}$ Palmer, ${ }^{1} \mathrm{~S}$ Travis, ${ }^{5} \mathrm{R}$ Logan, ${ }^{3} \mathrm{~T}$ Walsh, ${ }^{6} \mathrm{M}$ Murphy on behalf of TRIGGER Investigators. 'Translational Gastroenterology Unit, Oxford, UK; ${ }^{2}$ MRC CTU, London, UK; ${ }^{3}$ University of Edinburgh, UK; ${ }^{4}$ Western General Infirmary, Edinburgh, UK; ${ }^{5}$ University of Nottingham, Nottingham, UK; ${ }^{6} N H S B T$, Oxford, UK

10.1136/gutjnl-2014-307263.258 